\title{
LA PARODIA DE LOS CLÁSICOS EN LA HISTORIETA
}

\section{Dora Gladis Villalba}

\section{INTRODUCCIÓN}

En este escrito nos proponemos un acercamiento a la parodia de los textos homéricos: Ilíada y Odisea elaborada por Fontanarrosa en formato de historieta, según el siguiente:

\section{Plan de Trabajo}

1. Definición de parodia

2. La re-creación del inito clásico (según Luis Gil en Transmisión mítica)

3. La historieta, combinación de lenguajes (los origenes de la historieta y las relaciones de la misma con otros lenguajes)

4. La parodia de Homero en Fontanarrosa (desde la perspectiva de Yuri

Tinianov y Mijail Bajtin, por una parte, y desde la ética de la recepción, por otra.)

5. Conclusiones

Conviene aclarar que el énfasis está puesto en el texto escrito. No nos detuvimos a analizar el componente icónico pues ello excedería los objetivos del presente estudio. De todas formas lo hemos aludido en varias partes cuando lo consideramos necesario para la comprensión de la exposición.

\section{1) DEFINICIÓN DE PARODIA}

\subsection{Etimología del término}

Parodia significa canto o poesía parecida a otra, a la que imita burlescamente. Es un grecismo castellano. En idioma helénico se compone de: $\pi \alpha \rho \alpha ́ \alpha$ que, junto con $\pi \varepsilon \rho i$, $\pi \rho o ́, \pi \rho o ́ \zeta$ correspondiente al latín prae-, por-, per-, pertenece al gnupo $\pi \varepsilon i \rho \omega$ y tiene el significado fundamental de: 1) junto a: par- alelo, uno junto al otro (...) Los significados derivados pueden reducirse a dos: de junto a una cosa, por su parecido con ella, pero que no es genuina sino inferior, falsa, ilegítima, irregular; y de junto a una cosa, pero fuera de o más allá de ella. Tan unidos están ambos significados, que algunos ejemplos podrían pertenecer a cualquiera de ellos ${ }^{\mathrm{i}} \mathrm{y} \dot{\alpha} \varepsilon \dot{i} \delta \omega:$ cantar $^{\text {ii }}$

\subsection{Definiciones de parodia}

La parodia -según el diccionario" - "es la reproducción burlesca de una obra literaria fundada principalmente en el cambio de condición de los personajes"

Marmontel iv dice, por su parte: "El mérito y objeto de la parodia, cuando es buena, es hacer sentir, además de las más grandes cosas y de las más pequeñas, una relación que por su naturaleza y su novedad, nos causa una gran sorpresa. Contraste y semejanza, he ahí las fuentes 
de la buena burla, y es por esto que la perodia es ingeniosa y picante. Pero si en el asunto cómico no se presentan naturalmente las inismas ideas, los mismos sentimientos, las mismas imágenes, casi los mismos caracteres y las mismas pasiones que en el asunto serio, la parodia resulta forzada y fria. Son la exactitud de las relaciones, lo propio, lo natural, la verosimilitud que constituyen la sal, la gracia y la finura de la parodia."

Alfonso Reyes "asevera: "La parodia es una manera de crítica de acción" y "La parodia, especie de crítica en acción y que supone un estudio previo del modelo (...)."

Ya Aristóteles en su Poética se refiere a esta modalidad cuando afirma:

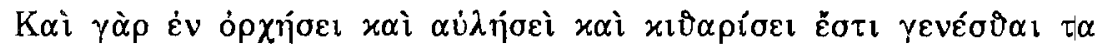

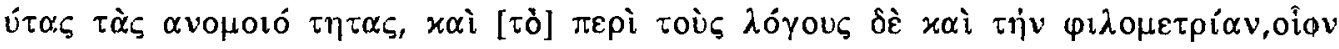

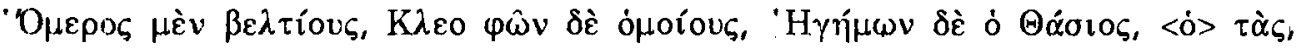

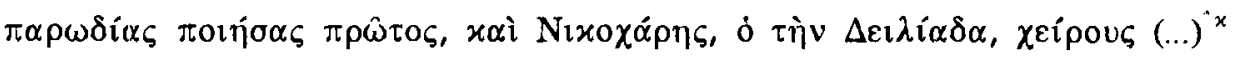

La traducción propuesta por V.García Yebra para este texto es la siguiente: "Pues también en la danza y en la mísica de flauta y en la citara pueden producirse estas desemejanzas, así como en la prosa y en los versos solos; por ejemplo, Homero hace a los hombres, mejores: Cleofonte, semejantes, y Hegemón de Taso; inventor de la parodia, $y$ Nicócares, autor de la Deliada, peores. "vii

A través de lo expuesto rescatamos estas notas significativas para caracterizar la parodia:

- revela un parecido con otra obra sin ser genuina

- hace a los hombres peores de lo que son

- reproduce burlescamente

- presenta una relación que por su naturaleza y novedad causa sorpresa

- su fundamento principal es el cambio de condición de los personajes

- Sus fuentes son el contraste y la semejanza

- logra el efecto burlesco por medio de la exactitud de relaciones, lo propio. lo natural y la verosimilitud

- es crítica en acción y supone estudio previo de un modelo 


\section{LA RE-CREACIÓN DEL MITO CLÁSICO}

\subsection{Connotaciones del mito griego.}

Según Luis Gil en su obra Transmisión mítica, los mitos griegos, adquieren lo que él denomina "connotaciones específicas", ya en época de Platón. Estas connotaciones son:

a) la tipificación: es la capacidad de "representar amplias categorías humanas en situaciones reductibles, a despecho de las cambiantes circunstancias, a los esquemas del relato mítico, es lo que llamamos tipificación [ ...]"viii

b) la intemporalidad: al encarnar al hombre en sí mismo, por sobre su circunstancia histórica, libre de la contingencia temporal, el mito se hace intemporal.

c) la recurrencia: es una consecuencia de las dos connotaciones anteriores. Tanto la tipificación como la intemporalidad posibilitan que el mito sea incesantemente plasmado en formas o en palabras por los artistas de todas las épocas.

\subsection{La reelaboración del mitn.}

Siempre siguiendo a Luis Gil, el autor re-creador de un mito toma una postura frente a él. Estal toma de postura presenta diversos actos:

a) integración: contituye la aprehensión de todos los elementos del mito para incorporarlos a su propia creación. "[ ...] la integración presupone aceptar la intemporalidad del mito."

b) proyección: traslada o desplaza temporal y/o espacialmente al mito, también. lo coloca en el sistema de valores propio de una época dada.

c) enfrentamiento: adopción de postura crítica frente al mito, "por razones ideológicas o temperamentales, [ ...] los tergiversa [ a los mitos] o degrada desfigurando su sentido. Los diversos grados de desmitificación que de esa toma de postura derivan desde la tragedia existencial $\left[\right.$...] a la parodia mítica. $[\ldots]^{\prime \prime} \times$

En estas tres acciones queda sintetizada la elaboración que pueda producir del mito el autor re-creador. Aclaramos que Fontanarrosa se ubica en la postura de enfrentamiento pues compone una parodia mítica.

\section{LA HISTORIETA, COMBINACIÓN DE LENGUAJES.}

3.1. Nacimiento de la historieta y posterior desarrollo. Con el propósito de contextualizar el análisis que hacemos de las historietas de Fontanarrosa nos parece necesario referirnos brevemente a los comienzos de este género.

Según O. Masotta la historieta nace el 16 de febrero de 1896 con la aparición de "Yellow Kid" en el diario World de Nueva York: "Desde el medio de una plancha que mostraba, y no sin humor, la vida turbulenta, los actos absurdos, el sadismo, la violencia y la 
inventiva de los habitantes de una miserable callejuela de bajo fondo, se distinguía la figura de un pibe vestido con un camisón que le llegaba a los pies, sobre el cual el dibujante calaba un texto inculto, y que miraba extrañamente al lector. Down Hogan's Alley o Hogan's Alley fue el primer título del excelente y corrosivo dibujo de Outcoult; pero cuando los técnicos del World introducen el amarillo en la gama de colores del suplemento y lo hacen sobre el vacío del camisón, el único sin color de la plancha, rebautizarán al personaje con el nombre de Yellow Kid (pibe amarillo) $[\text {... }]^{\mathrm{xi}}$

En sus principios, las diversas especies de historietas estaban ligadas al diario en que aparecian pues era el responsable del mismo el que daba la tónica de la tira. Esto cambia después de la segunda guerra mundial pues comienzan a aparecer los álbumes de historietas y los "books" de autor.

En el caso de los álbumes de historieta "entran en escena las historietas breves y otro tipo de necesidades narrativas. La historieta larga en entregad breves, como habían sido todas hasta aquel momento, vive de tensión más que de acción. debe hacer esperar al lector, provocar suspense obligarlo a comprar el diario al día siguiente o el próximo domingo para saber qué sucederá. En las historietas del álbum, en cambio, desde el primer momento la acción se hace fundamental, y con ella, en poco tiempo, la espectacularidad."xii

En lo que respecta a los "books" de autor, tanto el tema cuanto el desarrollo del mismo ofrecen más libertad pues la elección depende casi exclusivamente del autor quien elabora a título inclividual la o las historieta/s que se presentan a consideración del público.

En este último caso se encuadran la Ilíada y la Odisea de Fontanarrosa las que integran un texto llamado Los clásicos de Fontanarrosa. Para acentuar debidainente la unipersonalidad de la autoría, es el mismo Fontanarrosa quien agradece a los clásicos: "Roberto Fontanarrosa agradece la colaboración de Hernan Melville, Robert Stevenson, Walter Scott, Daniel Defoe, William Shakespeare, Homero, Miguel de Cervantes, Enriqueta Beecher Stowe y otros sin cuya inestimable, invalorable e involuntaria ayuda, no hubiese sido posible esta obra." xiii

\subsection{Los lenguajes de la historieta. Polifonía.}

Creemos, con Danielle Barbieri, que el lenguaje del cómic (historieta) establece relaciones con otros lenguajes ${ }^{\mathrm{xiv}}$ que pueden resumirse en cuatro tipos:

1. inclusión "(un lenguaje está incluído en otro, forma parte de otro)" ${ }^{\text {"xv }}$ Podemos incluir el lenguaje de la historieta dentro del lenguaje general de la narrativa.

2. generación. "Ell lenguaje del cómic es hijo de otros lenguajes", xvi como, por ejemplo, el de la ilustración, la caricatura o la literatura ilustrada, pero no es ninguno de ellos sino que se presenta como algo original.

3. convergencia. Se da en dos sentidos:

a) referencias comunes, por ejemplo, pintura, fotografia y gráfica;

b) áreas expresivas en común, por ejemplo, poesía, música, teatro y cine.

4. adecuación: "es la relación más interesante. Sucede cuando el cómic encuentra más sencillo remedar, reproducir en su interior otro lenguaje, para utilizar sus posibilidades expresivas, que tratar de construir unas posibilidades expresivas 'equivalentes'. es el caso en que, diclıo de otro modo, el cómic 'cita' otro lenguaje."xvi 
En Fontanarrosa y, sobre todo, en las dos producciones que nos ocupan, observamos estas cuatro relaciones, pero se nos hace sustantivo subrayar que la cuarta, la adecuación, es la que se presenta con más relevancia. Precisamente, lo que intenta hacer es "remedar" burlescamente el lenguaje épico con todas sus caracteristicas: particulares y propias, por ejemplo: Céfiro?"

- la adjetivación: “¿Qué prístiva canción llega a mis oídos cual olas impelidas por el

- los epítetos: ¿Qué os inquieta Ayax, hijo de Telamón?"

Pero el código verbal por sí sólo no logra el humor, sino que éste se manifiesta cuando inscribimos las frases en el contexto creado por los códigos concurrentes. De modo que, la combinatoria de todos los lenguajes en una relación que por su naturaleza y novedad causa sorpresa, "redondean" el efecto burlesco. De estas relaciones, asimismo, resulta la polifonía de la historieta.

\subsection{LA HISTORIETA, LA CARICATURA Y LA PARODIA.}

En el caso de la Iliada y la Odisea de Fontanarrosa, parodias evidentes del original homérico, deberíamos hacer una referencia más en el sentido de cómo el lenguaje de la imagen realiza un importante aporte en el logro de esta particular re-creación mítica. Para subrayar la naturaleza visible de sus clásicos griegos, Fontanarrosa acude a la caricatura. Desde el momento en que el dibujante puede, a través de ella, deformar y apuntar a un aspecto determinado de los personajes que le interesa, es posible que la utilice para expresar situaciones humorísticas. $Y$ así sucede en las dos tiras que concitan nuestra atención pues al presentar a los héroes griegos bajo la especie de caricaturas, logra acentuar el sentido paródico adjudicado a los textos de base.

\section{LA PARODIA DE HOMERO EN FONTANARROSA}

\subsection{Análisis desde la perespectiva de Tinianov y Bajtin 4,1.1. Yuri Tinianov}

Para delimitar el significado y alcances de "parodia", Tinianov la incluye dentro de las reflexiones acerca de las leyes de la evolución literaria. Para él, la parodia es un concepto que remite al de tradición y constituye un momento de corte, de ruptura con la tradición precedente. Además permite la transformación de la serie literaria y sirve de punto de partida para una nueva concepción de las reglas en que ésta evoluciona.

Donde se produce el corte citado debería haber parodia y, esto, es lo relevante en la historia de la literatura: el conjunto de estas parodias que posibilitan el corte. Para Titianov la parodia comprende dos etapas: 1) un punto de saturación de una escuela literaria y 2) la apropiación que de una escuela literaria hace otra escuela, otro autor y de la que surge una forma nueva. Por ello, la parodia revela un doble propósito: 1) mecaniza un procedimiento determinado y 2) organiza un nuevo material.

Además Titianov reconoce dos instancias en esta base: 1) la estilización (motivada) esto es, conformar a reglas convencionales la interpretación de objetos, de modo que sólo 
resalten las características esenciales y 2) la fase paródica (inmotivada) caracterizada por procedimientos de inversión (en Fontanarrosa, la inversión del mundo épico por desjerarquización de héroes y dioses y desfondamiento del mito) y repetición (por ejemplo, de estructura externa, lenguaje propio, etc..) injertados arbitrariamente en el texto parodiante. "[ ...] para que un procedimiento se torne perceptible, es necesario que aparezca inmotivado: ¿ Y qué es la parodia sino esta prodigiosa facultad de poner al desnudo lo que se roba de otro?"'

Las reflexiones de Tinianov resultan sumamente interesantes pero no alcanzan a demostrar que la parodia siempre resuleve un corte o ruptura con la tradición precedente.

\subsubsection{Mijail Bajtin}

Por su parte, M. Bajtin conecta la parodia con la novela, pues la relaciona con el proceso de constitución del género novelesco, la inserta en un continuum histórico. Define la especificidad del género novela y dice que ésta teje "una imagen del lenguaje ajeno." Precisamente, su rasgo distintivo consiste en un diálogo de los lenguajes. Diálogo que presenta nunerosas variantes: desde la pura imitación de un lenguaje hasta su destrucción, la parodia es vista como una de las formas de funcionamiento de esta representación del discurso ajeno que define al género novelesco. No es un género autónomo.

Más adelante afirma "Son otras la orientación y la posición de la conciencia paródica: ésta se orienta tanto hacia el objeto como hacia el discurso ajeno que lo parodia, discurso que se vuelve entonces representación, produciéndose en consecuencia una distancia entre el lenguaje y la realidad. "'kx

Pero el discurso parodiado no se muestra intacto en el discurso parodiante. No se linuta a una repetición pues hay una acción del discurso patodiante sobre el parodiado. En esta acción se dará, por ejemplo, la polifonía. En el caso de Fontanarrosa, los dos primeros cuadros de la Ilíada serian una manera de polifonia. Nos referimos al texto lingǘstico:

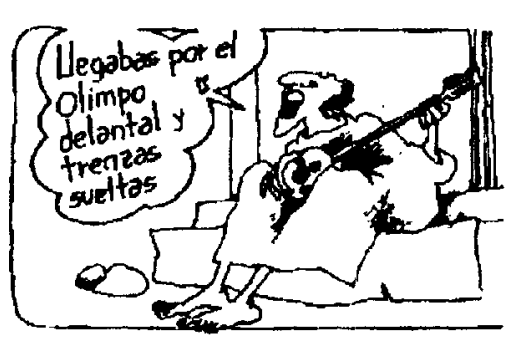

Fontanarrosa, Ilíada, cuadro ${ }^{\circ} 1$
El aedo homérico canta el tango "Malena"; por "debajo" de la letra del tango asoman alusiones mitológicas que quiebran la monotonía y la diversifican. Incoherencia que apunta al efecto cómico. 


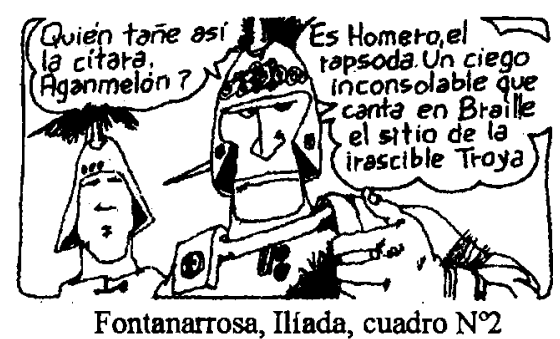

En el texto que pregunta aparece el nombre de Agamenón (texto parodiado) bajo la forma de Aganmelón (texto parodiante). La acción aqui se resuelve en una deformación del nombre heroico. Pero no se presenta una deformación caprichosa, pues tomado como grafia de minúscula y "lh" "haganmelón" es una forma del verbo hacer en imperativo, 3ra persona plural con enclisis pronominal "me" y "lo", en que este último pronombre presenta un reforzativo -n de plural antietimológico, normativamente incorrecto, pero de uso en la lengua sub-standard. De modo que varias voces confluyen para dar el toque burlesco, que será captado según la competencia linguística y cultural de cada uno.

En la respuesta, por otra parte, el héroe "sigue" formalmente (no secuencialmente) el texto épico pero se produce una interrupción en la unidad del discurso puesto que alude a Homero como "un ciego inconsoloble que canta en Braille..." La concurrencia de multiplicidad se da aquí por un salto en el tiempo, una irrupción futura en un texto que cronológicamente, sino lógicamente, no debe conocer el sistema Braille. La no-coherencia logra el efecto cómico.

Si lo vemos desde la perspectiva del narrador (Homero) se presenta una situación inverosímil pues él canta presenciando los sucesos de Troya. Y se sabe que históricamente, Homero vivió varios siglos después (al menos tres o cuatro) de la guerra. Nueva descolocación en la coherencia que lleva a la comicidad.

\subsection{LAPARODIA DESDE EL LECTOR: LA ESTÉTICA DE LA RECEPCIÓN}

\subsubsection{El "lector modelo" de Umberto Eco.}

Nos resta intentar una aptoximación a la parodia desde la perspectiva del lector Tomaremos, las ideas de U. Eco.

Según el citado autor el texto constituye una cadena de artificios expresivos que el destinatario debe actualizar. De modo que el destinatario se constituye en operador de esta cadena de artificios porque el texto se encuentra plagado de elementos no dichos y espacios en blanco. Para desentrañarlo, el lector debe realizar ciertos movimientos cooperativos, activos y conscientes tendientes a actualizarlo, pues el texto, precisamente, se emite para que alguien lo actualice incluso cuando no se espera que ese alguien exista concreta y empíricamente y que su competencia coincida necesariamente con la del emisor.

Por ejemplo 


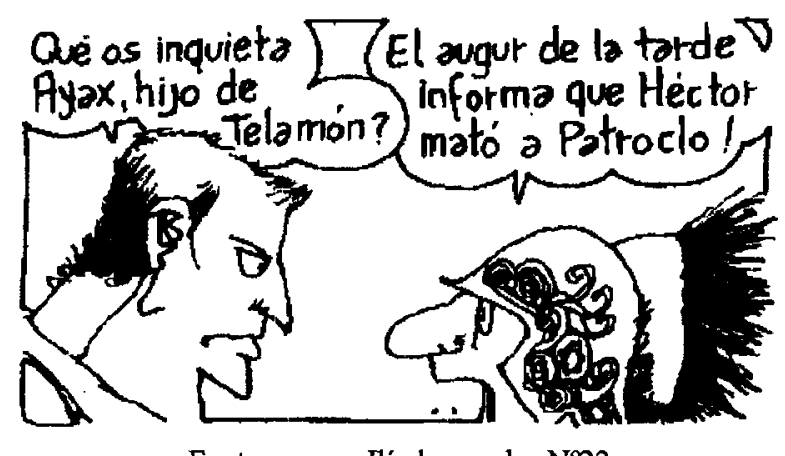

Fontanarrosa, Iliada, cuadro $\mathrm{N}^{2} 2$

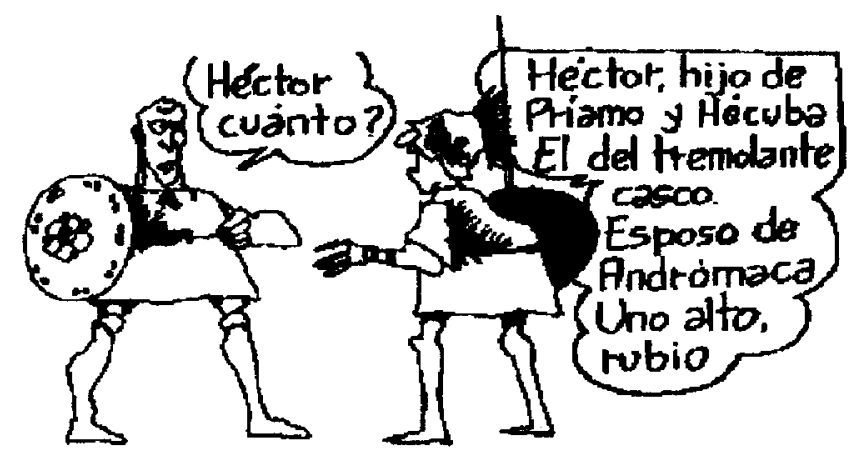

Fontanarrosa, Ilíada, cuadro N23

A la pregunta de Aquiles, Ayax brinda una serie de datos, el último de esa gradación: "Uno alto, rubio" nos remite a una película del actor francés Pierre Richard "Alto, rubio y con un zapato negro."

Aquí observamos que no todos los lectores necesariamente poseerán esa competencia. De todas formas, no descartamos la lectura ingenua de la que "escapan" estos recursos humorísticos construídos sobre la irrupción del futuro en la secuencia épica de Homero. 

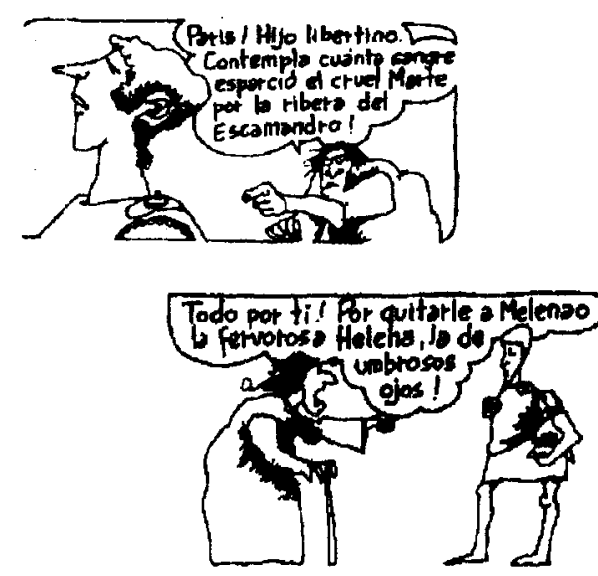

Esto sucede, según Eco, porque cada persona para decodificar, además de competencia lingüística necesita una competencia circunstancial diversificada. Sería el caso de los cuadros números 15 16- 17 y 18 (llíada). Diálogo Príamo Paris.

Fontanarrosa, Iliada, cuadros $\mathrm{N}^{\circ} 15-16-17-18$

El consejo en tono de reprimenda, emitido por Príamo “ $j Y$ bájate ...!" apunta al componente cultural homosexual que era aceptado en Grecia. Para captar la comicidad de la situación el lector deberá poseer una óptima competencia cultural diversificada con respecto a la Grecia Antigua y contrastarla con los patrones culturales de su propia época.

Por eso se habla legítimamente de la cooperación del lector como condición de la actualización del texto ya que el texto es un producto cuya suerte interpretativa debe formar parte de su propio mecanismo generativo.

El autor se figura un estratega que prevé los movimientos del otro y debe pensar aún en los movimientos casuales por medio del cálculo probabilístico. de este modo tendrá en cuenta una serie de competencias y supondrá que son las mismas de su lector. Asimismo deberá prever un lector modelo capaz de cooperar en la actualización textual de la manera prevista por él y de moverse interpretativamente, igual que él se ha movido generativamente. Los medios a utilizar los numerosos:

- elección de una lengua (que excluye a quien no la habla) Fontanarrosa,

- elección de un determinado patrimonio léxico y estilístico, por ejemplo; en

a) múltiples acepciones de un mismo término.

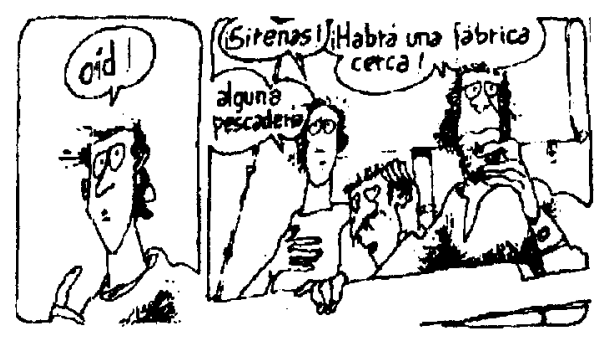

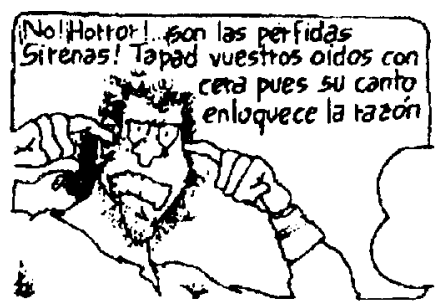

Fontanarrosa, La Odisea, cuadros N23-24- 25 
sirena: pito que se oye mucha distancia y que se emplea en los buques, automóviles, fábricas. etc. para avisar.

Sirena: Mitología. Ninfa marina con busto de mujer y cuerpo de ave, que extraviaba a los navegantes atrayéndolos con la dulzura de su canto.

Dichas acepciones llevan a establecer diversas relaciones humorísticas, como la siguiente: ¿Son las sirenas tan desafinadas que los compañeros de Ulises las confunden con sirenas?

a) "Caídas" en el lengıaje con respecto a la lengua épica:

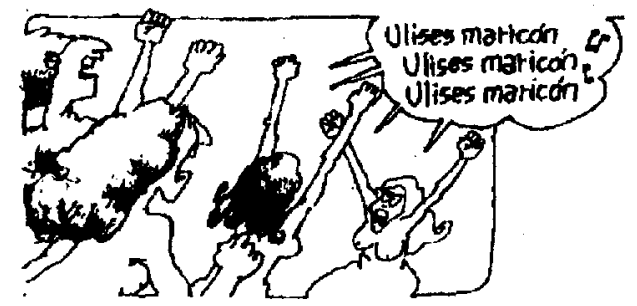

Fontanarrosa, La Odisea, cuadro $\mathrm{N}^{\circ} 32$.

Las sirenas califican a Ulises de "maricón" por no aceptar su convite erótico. Irrumpe el término informal en el registro épico $y$, por contraste, mueve a risa.

b) doble sentido en un vocablo.

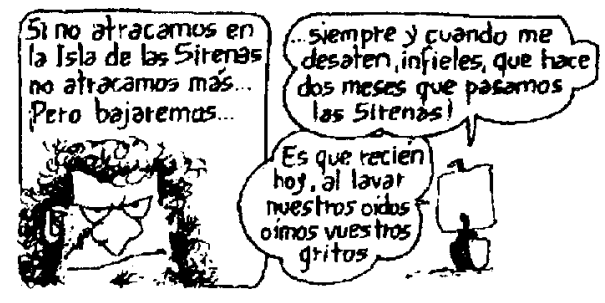

Fontanarrosa, La Odisea, cuadros N³4- 35.

El verbo atracar significa propiamente "arrimarse un navío a otro o a tierra", pero Ulises lo emplea coloquialmente con el sentido de "avance amoroso" o, "escarceos corporales destinados a manifestar fisicamente el amor", con una gran carga de libido, picardía y, hasta de grosería en el uso, en algunos casos. Resulta sorprendente la inclusión de este vocablo en el parlamento del héroe homérico por resultar anacrónico y por aparecer en un registro que no le corresponde. Así también logra la comicidad.

- marcas dintintivas de género. 
En este sentido, Fontanarrosa conserva dichas marcas pero con variantes "enfrentadas" al modelo. Por ejemplo con la variación de epitetos: "Voluble Minerva" "Belicosa Minerva" (Cfr.: Minerva, la de los ojos de lechuza)

- restrición del marco geográfico.

En el caso de la Iíada, nuestro autor se refiere precisamente a Troya.

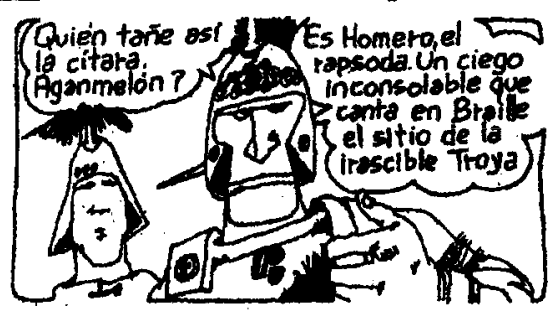

Fontanarrosa, Ilíada, cuadro N2.

En la Odisea, propone un juego de oposición Itaca/ Itaka basado en la semejanza de las consonantes $/ \mathrm{c} / \mathrm{y} / \mathrm{k} /$ en espafiol. Sobre todo porque "Itaka" es la denominación de un arma de fuego. (Nueva competencia, nueva comicidad).

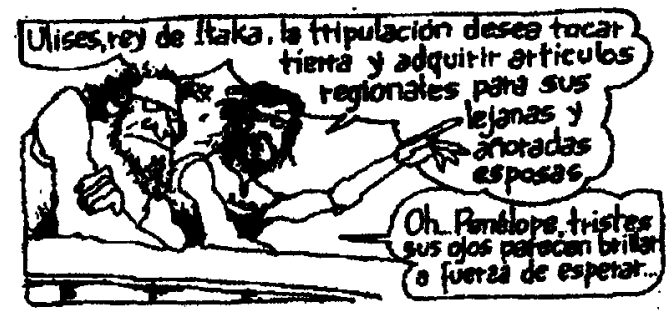

Fontanarrosa, La Odisea, cuadro $N 7$.

Siempre siguiendo a Eco, diremos que las interpretaciones que hacen los lectores de un texto son diferentes y múltiples, pero el autor tratará de que estas interpretaciones repercutan unas sobre otras de modo que no se excluyan sino que, se enriquezca y refuercen reciprocamente.

Para comprender el texto de Fontanarrosa el lector debe contar con una competencia circunstancial diversificada puntual en la que se contemplen: el concepto de parodia, el sentido y definición del mito, el conocimiento de la epopeya homérica....Sólo de este modo podrá cooperar para reconstruir. Nuestro humorista, supuestamente, ha "construido" su lector modelo a través de los siguientes items:

- selección de grados de dificultad linguística. Por ejemplo: cuadro N039 (Odisea). 


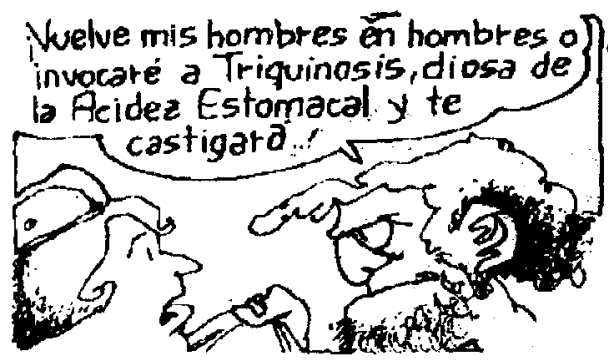

Fontanarrosa, La Odisea, cuadro N ${ }^{\circ} 39$
Incluye en el parlamento de Ulises la palabra "triquinosis" del vocabulario médico (.) ("enfermedad ocasionada por el desarrollo y fijación de triquinas en el organisıno. En el hombre se debe a la ingestión de carne de cerdo infectada" que, a su vez, proviene de la raíz griega

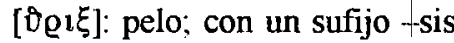
que indica dinámica de proceso)

Además con la grafia mayúscula la personifica y la vuelve una deidad. Sólo el lector que conozca medianamente ambos campos (el de la cultura clásica y el vocabulario médico de enfermedades) podrá intentar la actualización del texto por medio de la actividad interpretativa.

- riqueza de referencias. En este caso estarian, por ejemplo los cuadros númcro $1,6,12,14,20,35, y 43$ (líada) en que se resuelve la participación del aeda como "contrapunto" de la voz del relato.

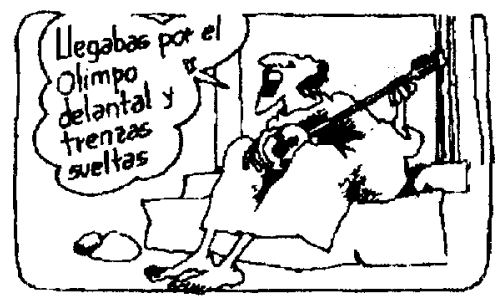

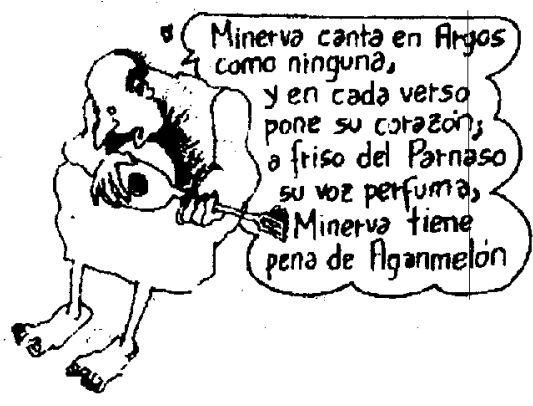

Fontanarrosa, Ilíada, cuadros $\mathrm{N}^{\circ} 1-6$ 


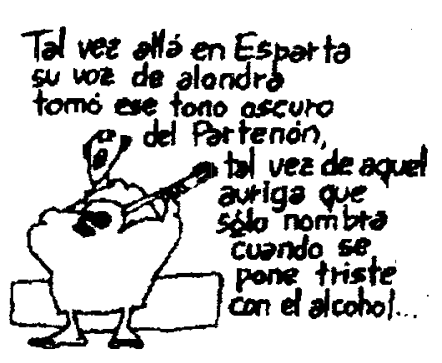

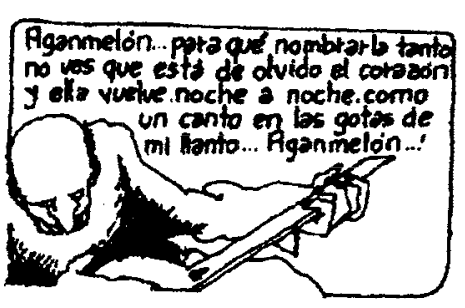

Fontanarrosa, Ilíada, cuadros $N^{\circ} 12-14$
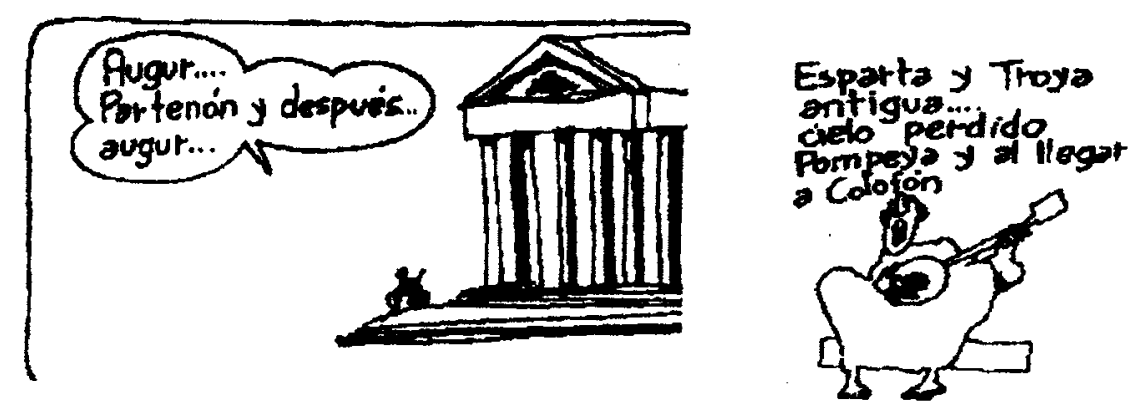

Fontanarrosa, Ilíada, cuadros N20- 35. 


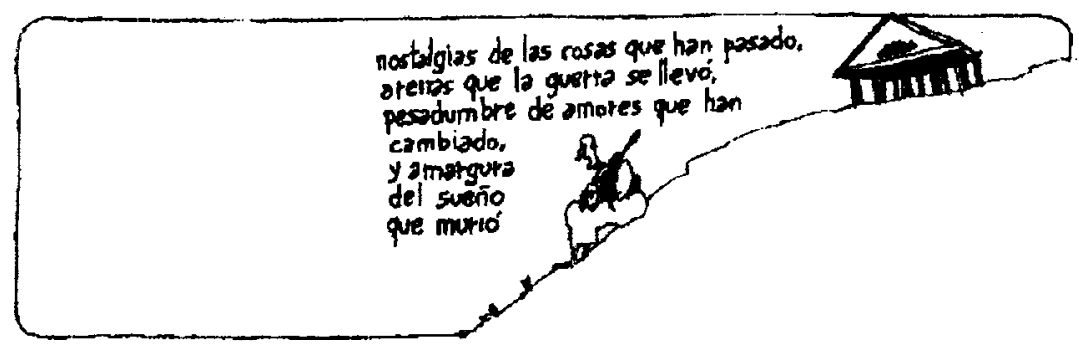

Fontanarrosa, Iliada, cuadro $\mathrm{N}^{\circ} 43$.

Lo curioso es que este aeda recupera información para el lector pero lo hace a través de una letra de tango o letras de tangos. Se infiere aqui que toma dos composiciones: "Malena": por ejemplo cuadro No12: "Tal vez allá en Esparta/ su voz de alondra/ tomó ese tono oscuro/ del Partenón,/ tal vez de aquel auriga/ que sólo nombra / cuando se pone triste con el alcohol."

O si no "Sur": por ejemplo cuadro No35: "Esparta y Troya antigua/ cielo perdido/ Pompeya y al llegar a Colofón", en donde el autor crea un "mundo coincidente" en el que confluyen épocas, circunstancias, personajes que se identifican, etc.

- inserción de claves, remisiones y posibilidades

a) Claves: las claves están dadas por las macrorreglas textuales pues nuestro autor OMITE: sólo toma el tópico textual fundamental (la cólera por ejemplo en Ilíada): SELECCIONA: dentro de ese tópico toma lo más significativo pero que permite recuperar la información omitida; GENERALIZA: da un concepto abarcador de todo el texto. Plasma en lo textual le genérico de la epopeya: el comportamiento de los héroes $y$, finalmente. CONSTRUYE o INTEGRA: sustituye vieja información por nueva información. Con esto nos permite alcanzar la macroestructura del texto o su estructura semántica global.

Si deseamos graficar las claves observamos que en este proceso Fontanarrosa toma de la Ilíada los cantos I (peste, cólera); III (las recriminaciones de Héctor a Paris, aquí Príamo a Paris); IX: (Ayante Telamonio recrimina, aquí anuncia la muerte de Patroclo que en la obra homérica se encuentra en el canto XVIII y en boca de Antíloco). XIX (renunciamiento de la cólera) y XX (combate de los dioses)

Con respecto a la Odisea, los cantos que trabaja son: XXIII y II (para comenzar, reconocimiento de Ulises por Penélope y la tela que ésta teje); IX (Cíclope); XII (Sirenas) y X (Circe).

El humorista ha operado sobre la sustancia homérica siguiendo pautas propias alternando el orden de los episodios según las macrorreglas- clave. 
b) remisiones: en los cuadros números 2 y 7 (Odisea)
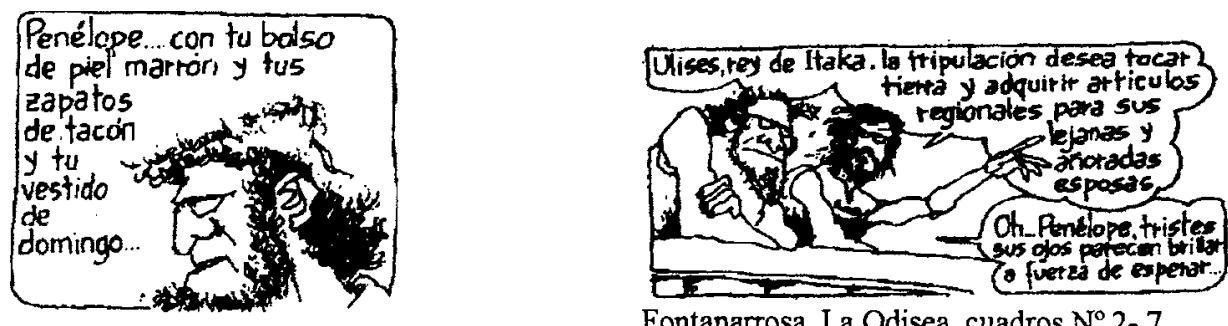

Fontanarrosa, La Odisea, cuadros $\mathrm{N}^{\circ}$ 2- 7.

La lectura de ambos parlamentos nos remite a otro texto: el de la canción "Penélope", interpretada por Joan Manuel Serrat, entre otros.

Desearía destacar que el texto parodiante es, en sí mismo, polifónico pues concurren en él, muchas voces. Pero, como en ningún otro, se observa la transtextualidad entendida (según G. Giiette) como el diálogo secreto o manifiesto de un texto con otro u otros textos.

Ilíada.

Lo mismo ocurre con los tangos que canta -"en tiempo de epopeya"- el aeda de la

c) posibilidades.

En cuanto a la categoria de lo "posible" en ambas epopeyas los finales se apartan del clásico y el autor, a través de la re-creación vista como "posibilidad", nos sorprende en los dos casos con finales insólitos e inesperados. 

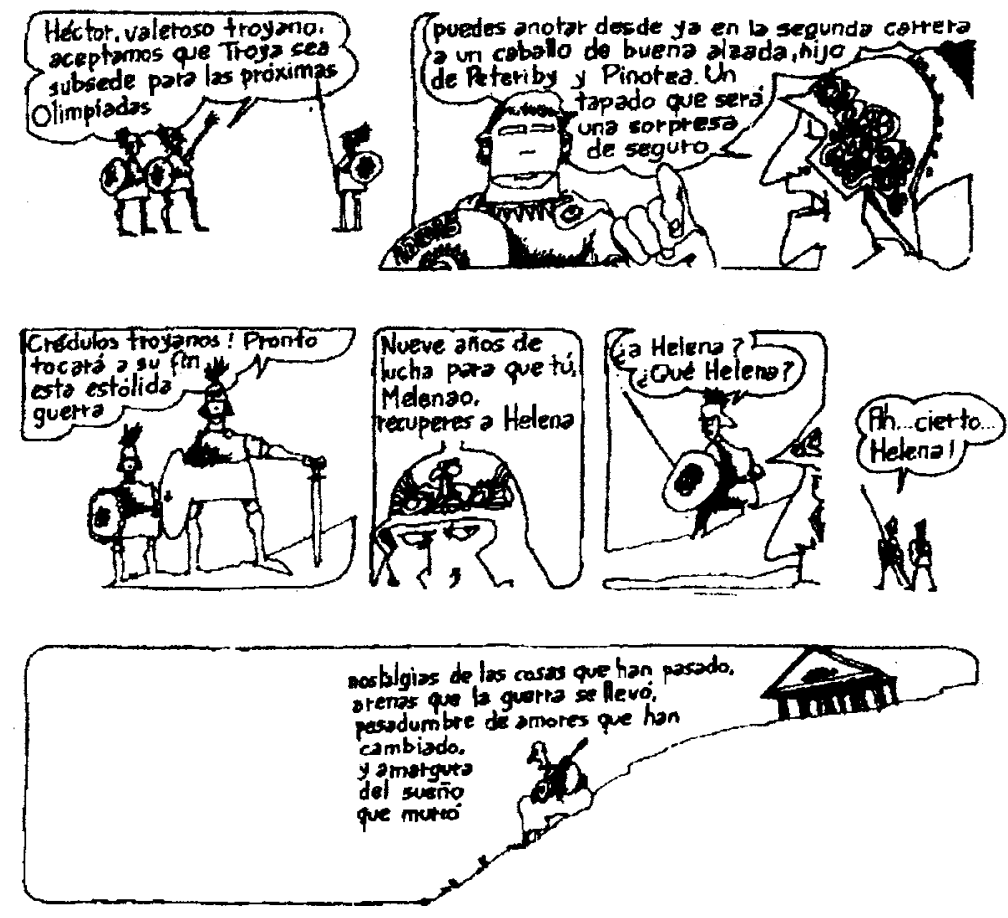

Fontanarrosa, Lliada, cuadros N'37 a 43. 

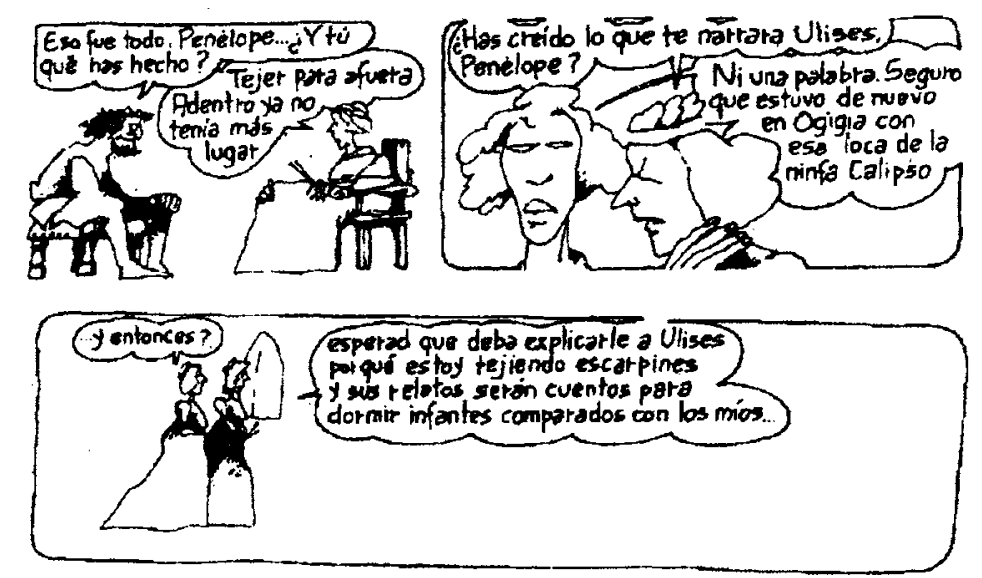

Fontanarrosa, La Odisea, cuadros N 42 a 44

Hasta aquí nos hemos colocado bajo la piel del lector con la guia de Umberto Eco.

Y finaliza nuestro análisis de la parodia de Fontanarrosa. De ningún modo hemos agotado las "miradas" sobre el texto ni las hipótesis de lectura que son susceptibles de ser enunciadas desde muchísimas perspectivas. Es el límite impuesto al trabajo el que nos lleva a detenernos en este punto.

\section{Conclusiones.}

5.1. Pensamos que Fontanarrosa ha logrado una acertada parodia de Homero resultado del encuentro dialéctico entre el texto homérico y el texto parodiante.

5.2. Como autor- recreador ha incorporado las connotaciones del mito griego y lo ha reelaborado desde la óptica dominante de la acción de enfrentamiento.

5.3. $\mathrm{Al}$ ser Homero un autor parodiado elegido libremente e incorporado a un "book" de autor, las posibilidades de libertad en la re-creación quedan aseguradas pues dependen enteramente del arbitrio y de la capacidad del humorista.

5.4. Las relaciones propias de la historieta con otros lenguajes ponen su acento en la adecuación pues se intenta la mímesis de un lenguaje en el sentido prístino del término "imitar" (que no es reproducir fielmente sino crear tomando como base un modelo).

5.5. Aunque en este trabajo no nos ocupamos exhaustivamente del aspecto icónico, debemos decir que la caricatura, sobre todo, contribuye a acentuar la idea de texto paródico. Esto si transponemos la definición de parodia: "una canción parecida a otra pero no genuinia, sino falsa, ilegítima, irregular" a la delimitación de caricatura entendida como modo de representar personajes y objetos que destacan ciertas características, deformándolas hasta llegar, incluso, al grotesco y, en este caso, con el fin de poner de manifiesto situaciones humorísticas. 
5.6. Tanto Yuri Tinianoy como Mijail Bajtin ofrecen interesantes aproximaciones, desde el punto de vista del texto en sí con respecto a la parodia y se revelan como útiles instrumentos a la hora de analizar el texto de Fontanarrosa.

5.7. En cuanto a los elementos ofrecidos por la "estética de la recepción" creemos que ningún texto como el texto paródico necesita tanto del 'movimiento cooperativo' del lector para ser interpretado por la cantidad de competencias que entran en juego ni bien comienza la relación autor- texto- lector.

5.8. Nos hemos propuesto una "mirada" al texto parodiante de Fontanarrosa y hemos dado una serie de pasos ordenados tendientes a la consecución de este objetivo. En homenaje al autor re-creador debemos decir que esta mirada fue posible gracias a la singularidad insoslayable que hace único al texto literario.

\section{CITAS}

${ }^{i}$ MENDIZÁBAL, R. Manual de la Lengua griega. $5^{\text {a }}$ ed. Madrid, Razón y Fe, 1963, p. 230. (el subrayado es del autor)

"MENDIZÁBAL, R. ; op. cit; p. 160.

ii) - ENCICLOPEDIA UNIVERSAL ILUSTRADA. Europeo-Americana. Barcelona, Espasa Editores, 1921-1982, t. LXII, p.237.

iv op. cit., t. XLII, p.237.

" REYES, A. La crítica en la edad ateniense. México, F.C.E., 1941, p. 120 y p. 150. respectivamente

${ }^{v i}$ ARISTó TELES. Poética; ed. trilingüe por V. Garcia Yebra. Madrid, Gredos, 1974, pp. 13132,1448 a. y ss.

vii GARCÍA YEBRA, V. (en ARISTÓTELES, op. cit. , p. 132).

${ }^{v i i i}$ GIL, Luis. Transmisión mítica. Barcelona, Planeta, 1975, p.15.

${ }^{i *}$ GIL, Luis; op. cit., p. 17.

${ }^{x}$ GIL, Luis; op. cit., p. 18.

${ }^{x i}$ MASOTTA, Oscar. La historieta en el mundo moderno. Barcelona, Paidós, 1982, pp. 23-24

vii BARBIERI, Danielle. Los lenguajes del cóınic; trad. J.C. Gentile Vitale. Barcelona, Paidós, 1993. 